\title{
THE EVALUATION OF THE POTENCY OF NEWLY DEVELOPED OXIMES (K727, K733) AND TRIMEDOXIME TO COUNTERACT ACUTE NEUROTOXIC EFFECTS OF TABUN IN RATS
}

\author{
Jiř́ Kassa, Jana Hatlapatková, Jana Žd'árová Karasová
}

Department of Toxicology and Military Pharmacy, Faculty of Military Health Sciences, University of Defense, Hradec Králové, Czech Republic

Summary: Aim: The ability of two newly developed oximes (K727, K733) to reduce tabun-induced acute neurotoxic signs and symptoms was evaluated and compared with currently available trimedoxime in rats. Methods: The neuroprotective effects of the oximes studied combined with atropine on Wistar rats poisoned with tabun at a lethal dose $(380 \mu \mathrm{g} / \mathrm{kg}$ i.m.; $90 \%$ of $\mathrm{LD}_{50}$ value) were evaluated. Tabun-induced neurotoxicity was monitored by the functional observational battery consisting of 38 measurements of sensory, motor and autonomic nervous functions at 2 hours following tabun challenge. Results: All tested oximes combined with atropine enable tabun-poisoned rats to survive till the end of experiment. Both newly developed oximes (K727, K733) combined with atropine were able to decrease tabun-induced neurotoxicity in the case of lethal poisoning although they did not eliminate all tabun-induced acute neurotoxic signs and symptoms. Conclusion: The ability of both novel bispyridinium oximes to decrease tabun-induced acute neurotoxicity was slightly lower than that of trimedoxime. Therefore, the newly developed oximes are not suitable for the replacement of commonly used oximes such as trimedoxime in the treatment of acute tabun poisonings.

Keywords: Tabun; Neurotoxicity; Functional observational battery; Oximes; Rats

\section{Introduction}

Highly toxic organophosphorus compounds called nerve agents have been developed as chemical warfare agents. They exert their toxic effects primarily via irreversible inhibition of the enzyme acetylcholinesterase (AChE, EC 3.1.1.7) by phosphylation (phosphorylation or phosphonylation) of its active site serine in the central and peripheral nervous system. The inhibition of AChE after exposure to nerve agents leads to the accumulation of the neurotransmitter acetylcholine in the synaptic cleft and to subsequent overstimulation of both muscarinic and nicotinic cholinergic receptors that results in excitotoxicity, seizures, brain damage, long-term behavioral aberrations including cognitive deficits and other signs and symptoms of acute cholinergic crisis. The death is usually caused by central and peripheral respiratory failure resulting from bronchospasm, excessive bronchial secretion, paralysis of respiratory muscles, and depression of brain respiratory centers (1-3).

A current standard treatment of poisoning with nerve agents usually consists of a combined administration of an anticholinergic drug (preferably atropine) and an oxime (preferably pralidoxime or obidoxime). Generally, anticholinergics are used for relieving muscarinic signs and symptoms whereas oximes are used for reactivation of nerve agent-inhibited $\operatorname{AChE}(2,4,5)$. Unfortunately, cur- rently available antidotal treatment is not able to sufficiently counteract acute toxic effects of nerve agents because of limited ability of oximes to reactivate nerve agent-inhibited AChE, especially in the case of acute poisoning with tabun, soman and cyclosarin (6-8). Tabun (O-ethyl-N,N-dimethyl phosphoramidocyanidate) is one of the most resistant nerve agents. Its deleterious effects are extraordinarily difficult to antagonize due to the changes in hydrogen bonding and conformational changes of AChE-tabun complex in the AChE active site that make the nucleophilic attack of oximes very difficult $(9,10)$.

In the case of severe intoxication, some nerve agents including tabun can cause centrally mediated seizure activity that can rapidly progress to status epilepticus and contribute to profound brain damage that is associated with long-lasting neurological and psychological injuries $(11,12)$. Therefore, the ability of antidotes to counteract acute neurotoxic effects of nerve agents and prevent nerve agent-poisoned organisms from irreversible lesions in the central nervous system (CNS) is very important for the successful antidotal treatment of acute nerve agent poisonings. Generally, the oximes exert more potent effects in the peripheral nervous system compared to CNS due to their low penetration across the blood-brain barrier (BBB). Although the percentage of reactivation of nerve agent-inhibited $\mathrm{AChE}$ in the brain is lower compared to the peripheral nervous system, the role 
of reactivation of nerve agent-inhibited $\mathrm{AChE}$ in the brain is important for survival from nerve agent exposure (2).

As currently available antidotal treatment consisting of atropine and commonly used reactivator of inhibited AChE (pralidoxime, obidoxime, trimedoxime) is not able to sufficiently counteract acute toxic effects of tabun because of low ability of oximes to reactivate tabun-inhibited $\mathrm{AChE} \mathrm{(8),} \mathrm{the}$ replacement of commonly used oximes with a more effective oxime has been a long-standing goal for the treatment of tabun poisoning. Therefore, we are still searching for a more efficacious oxime able to sufficiently reactivate tabun-inhibited AChE. For this purpose, two novel oximes, K727 [naphtylene-2,7-diyl-bis(2-hydroxyiminomethylpyridinium) dibromide] and K733 [4-(ethylcarboxyl)-2'-(hydroxyiminomethyl)-1,1'-(phenylene-1,3-diyl)-bispyridinium dibromide] (Figure 1), were synthesized at our Department of Toxicology and Military Pharmacy to improve the efficacy of antidotal treatment of tabun poisoning. They were developed based on the structure-activity relationship study and they were chosen based on the data obtained from molecular docking and in vitro evaluation of their ability to reactivate acetylcholinesterase inhibited by organophosphorus compounds. The evaluation of their potency to reactivate tabun-inhibited hAChE using in vitro methods showed that the reactivating efficacy of both newly developed oximes is comparable with trimedoxime and obidoxime.

The aim of this study was to compare the potential neuroprotective effects of two newly developed oximes (K727, K733) with trimedoxime in combination with an anticholinergic drug atropine in tabun-poisoned rats. The tabun-induced neurotoxic signs were determined using a functional observational battery, a non-invasive and relatively sensitive type of neurological examination for a wide range of neurobiological functions including measurements of sensory, motor and autonomic nervous functions (13).

\section{Materials and methods}

Animals
Male albino Wistar rats weighing $220-250 \mathrm{~g}$ were pur-
chased from VELAZ, Czech Republic. They were kept in
climate- and access-controlled rooms $\left(22 \pm 2^{\circ} \mathrm{C}\right.$ and 50
$\pm 10 \%$ relative humidity) with the light from $07: 00 \mathrm{hr}$ to
19:00 hr and were allowed access to standard food and tap
water ad libitum. The rats were acclimatized in the labora-
tory vivarium for 14 days before starting the experiments,
and they were divided into groups of 8 animals. Handling
of the experimental animals was done under the supervision
of the Ethics Committee of the Faculty of Military Health
Sciences, Czech Republic.

\section{Chemicals}

Tabun was obtained from the Military Technical Institute in Brno (Czech Republic) and was 90\% pure as assayed by acidometric titration. The basic solution of tabun $(1 \mathrm{mg} / 1 \mathrm{~mL})$ was prepared in propyleneglycol three days before starting the experiments. Actual solution of tabun was prepared from its basic solution with the help of saline immediately before administration. All oximes studied (Figure 1) were of 98.5\% purity and were synthesized at the Department of Toxicology and Military Pharmacy of the Faculty of Military Health Sciences in Hradec Kralove (Czech Republic). Their purities were analyzed using HPLC (14). All other drugs and chemicals of analytical grade were obtained commercially (Sigma Aldrich, Prague, Czech Republic) and used without further purification. The saline solution $(0.9 \% \mathrm{NaCl})$ was used as a vehicle. All substances were administered intramuscularly (i.m.) at a volume of $1 \mathrm{~mL} / \mathrm{kg}$ body weight (b.w.).

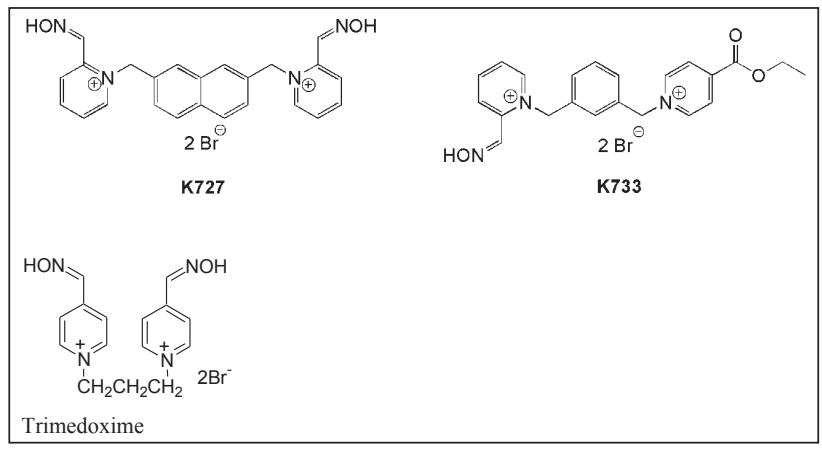

Fig. 1: Chemical structure of oximes studied.

\section{In vivo experiments}

Tabun was administered i.m. at a lethal dose $(380 \mu \mathrm{g} / \mathrm{kg}$ b.w. $-90 \% \mathrm{LD}_{50}$ ). The relatively high dose of tabun was used to achieve maximum number of tabun-induced neurotoxic signs and symptoms at the time when the neurotoxicity of tabun was monitored by the functional observational battery. One minute following tabun poisoning, the rats were treated i.m. with atropine sulfate $(10 \mathrm{mg} / \mathrm{kg}$ b.w. corresponding to $1 \%$ of its $\mathrm{LD}_{50}$ value) in combination with the oxime $\mathrm{K} 727$, K733 or trimedoxime at equitoxic doses corresponding to $5 \%$ of their $\mathrm{LD}_{50}$ values (15). The neurotoxicity of tabun was monitored using the functional observational battery at 2 hours following tabun poisoning. This time interval was chosen because we wanted to assess the maximal ability of antidotal treatment to avoid or at least diminish all tabun-induced neurotoxic signs and symptoms during acute cholinergic crisis when the full clinical picture of acute poisoning with tabun is developed and visible. The evaluated markers of tabun-induced neurotoxicity in experimental animals were compared with the parameters obtained from control rats given saline instead of tabun and antidotes at the same volume ( $1 \mathrm{~mL} / \mathrm{kg}$ b.w.). In addition, the markers of tabun-induced neurotoxicity in treated tabun-poisoned rats were compared with the parameters obtained from non-treated tabun-poisoned rats. 


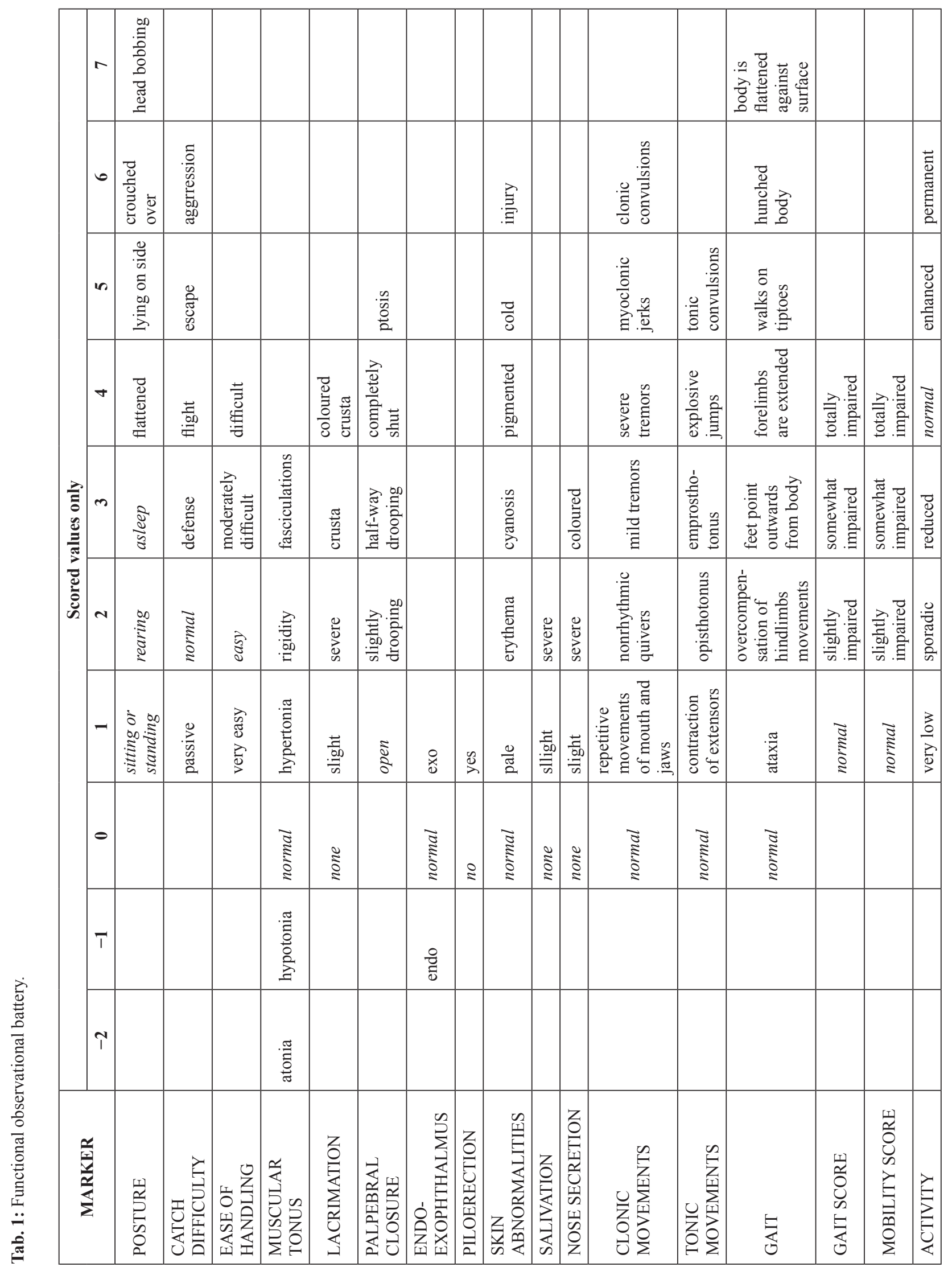




\begin{tabular}{|c|c|c|c|c|c|c|c|c|c|c|}
\hline 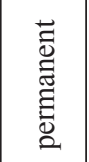 & & & & & & & & & & \\
\hline $\begin{array}{l}\vec{\Xi} \\
\stackrel{0}{E} \\
\bar{\Xi} \\
\bar{\Xi}\end{array}$ & & $\begin{array}{l}\frac{n}{0} \\
\frac{\tilde{d}}{0}\end{array}$ & $\begin{array}{l}\frac{n}{2} \\
\frac{\bar{t}}{0}\end{array}$ & 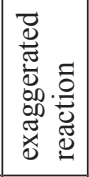 & 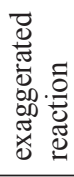 & 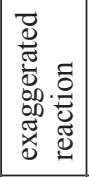 & 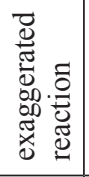 & & & \\
\hline 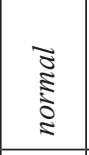 & & 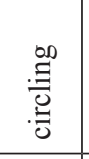 & 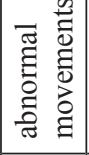 & 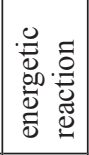 & 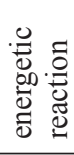 & 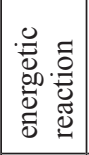 & 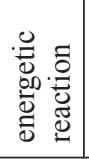 & & & 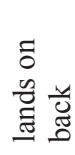 \\
\hline 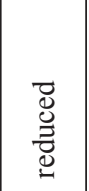 & & 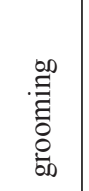 & 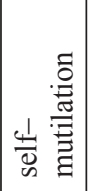 & 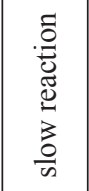 & 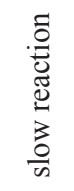 & 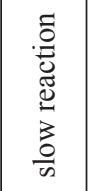 & 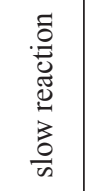 & & & $\begin{array}{l}\frac{\tilde{z}}{w} \\
\tilde{0} \\
\tilde{y} \\
\text { E }\end{array}$ \\
\hline 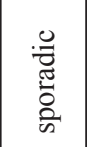 & 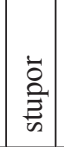 & 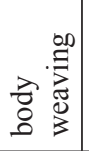 & 형 & $\begin{array}{l}\text { Z } \\
\text { ఏ }\end{array}$ & $\begin{array}{l}\bar{\Xi} \\
\text { ఏ } \\
\vdots\end{array}$ & $\begin{array}{l}\bar{\Xi} \\
\vdots \\
\vdots\end{array}$ & $\begin{array}{l}\bar{\Xi} \\
\vdots\end{array}$ & & & 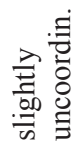 \\
\hline$\frac{3}{0}$ & 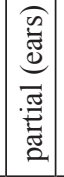 & 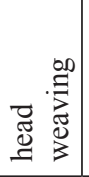 & ت્ّ & 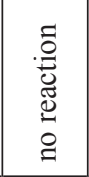 & 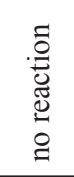 & 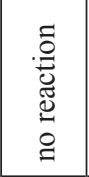 & 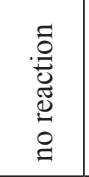 & 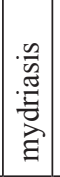 & 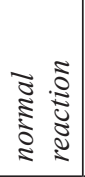 & 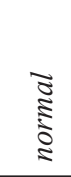 \\
\hline & $\cong$ & $\cong$ & $\stackrel{\Xi}{\cong}$ & & & & & $\begin{array}{l}\bar{Z} \\
\vdots \\
\vdots \\
\vdots\end{array}$ & 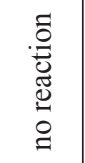 & \\
\hline & & & & & & & & 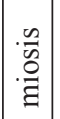 & & \\
\hline 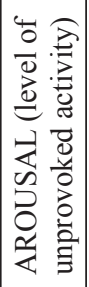 & 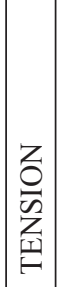 & 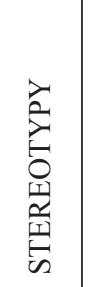 & 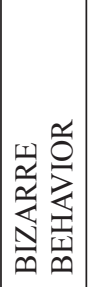 & 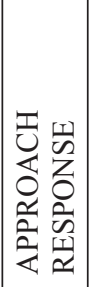 & 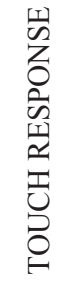 & 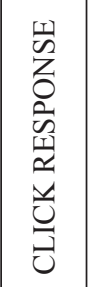 & 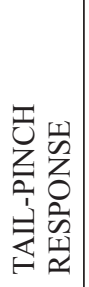 & 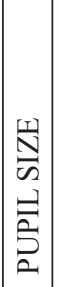 & 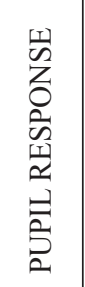 & 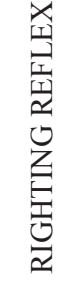 \\
\hline
\end{tabular}




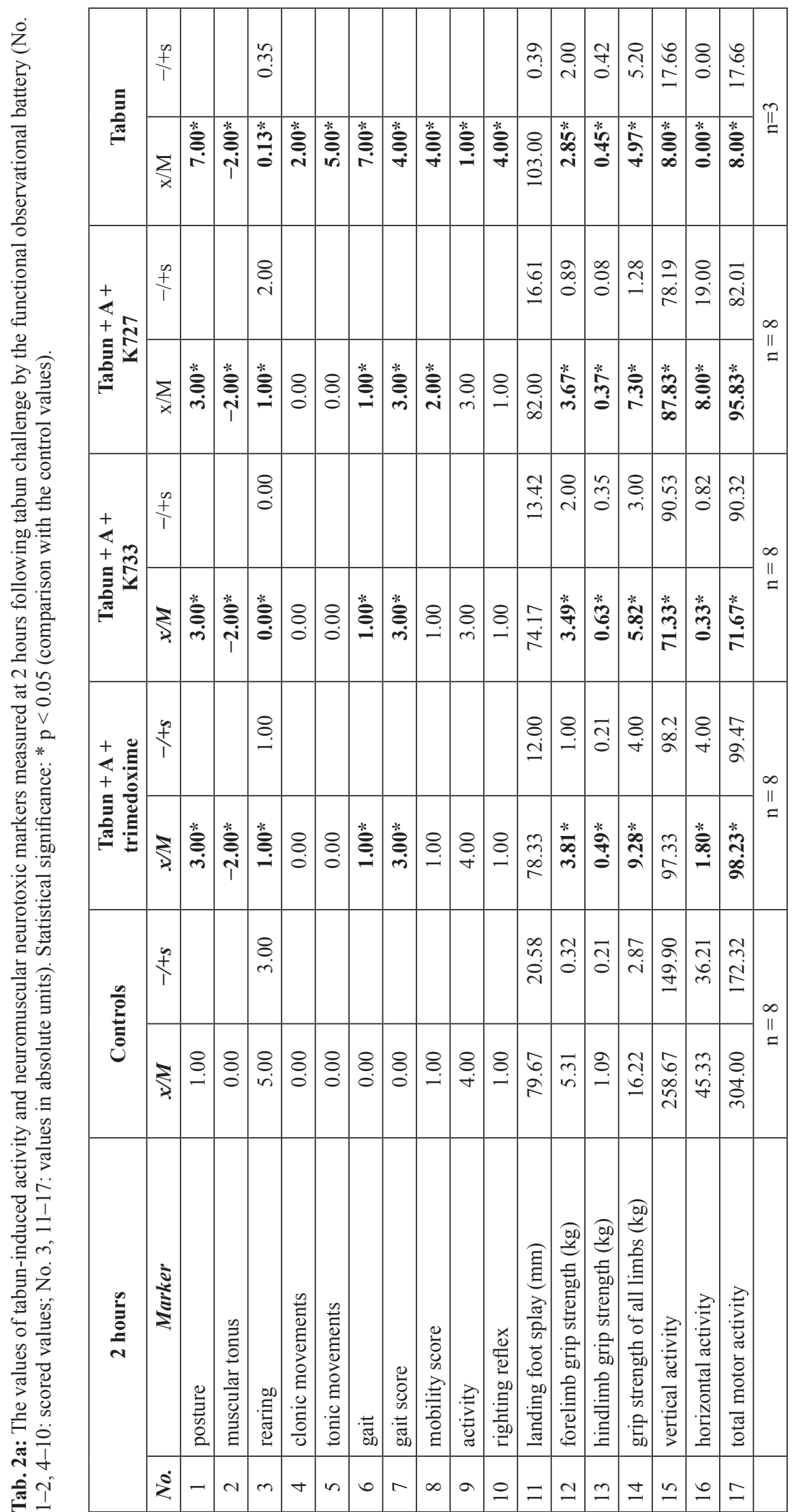



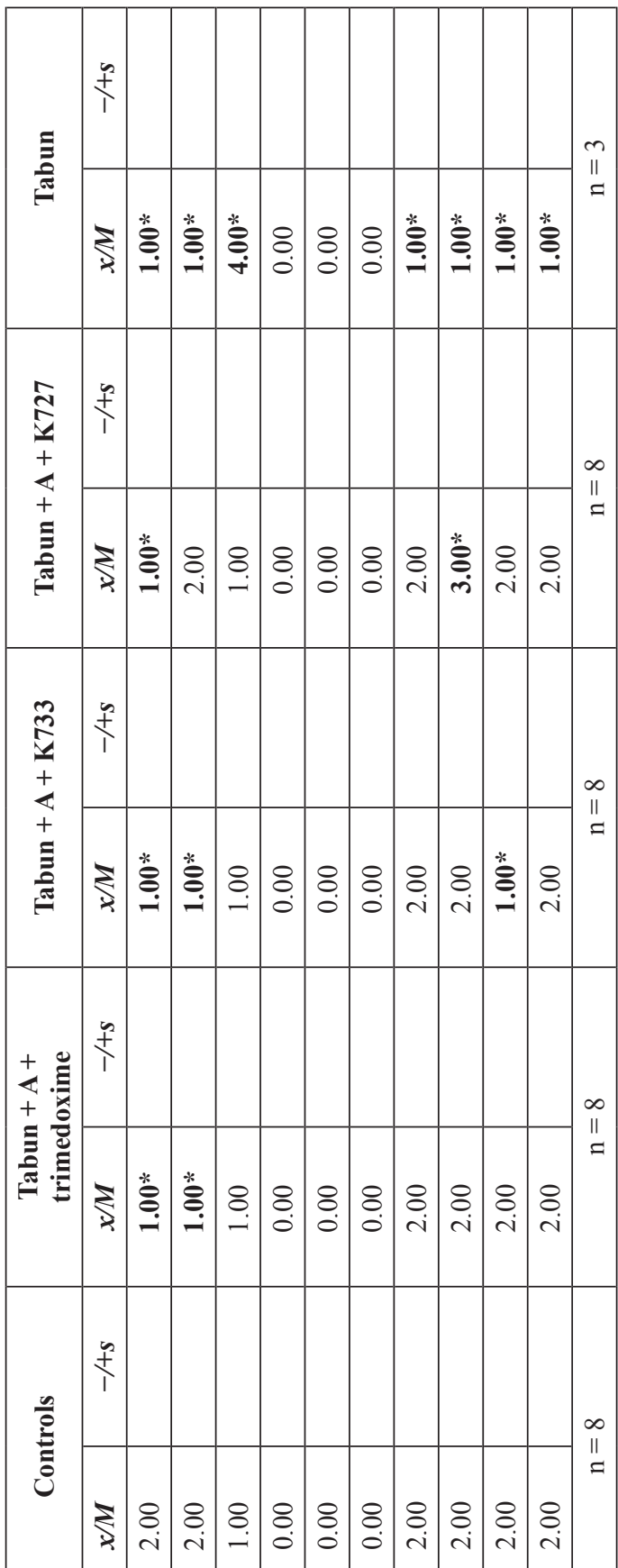

政。

s.

है

言量

흐음

旁 $\frac{\text { क }}{3}$

氖

กิ่

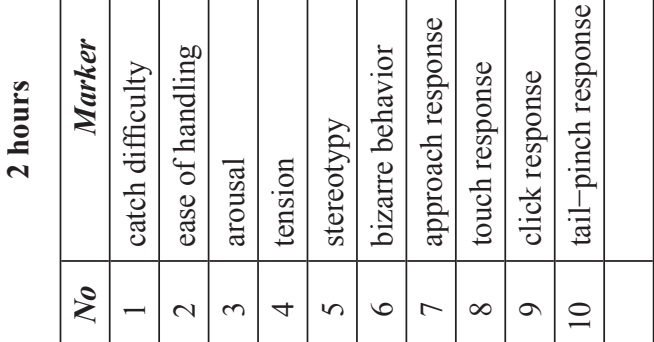

更
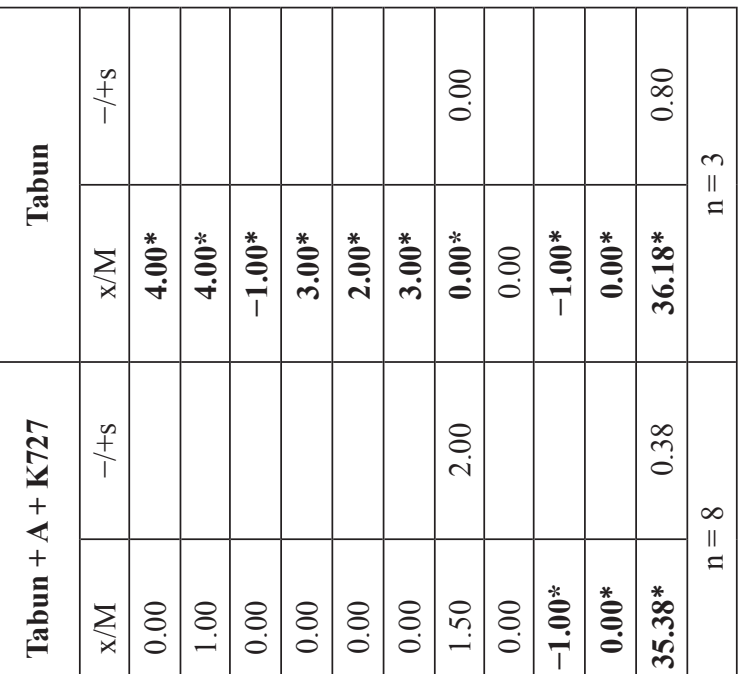

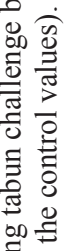

. 응

言

产

으.

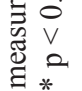

竞 *

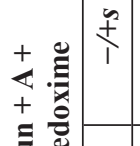

F.

$\underset{8}{\stackrel{8}{+}}$

$\stackrel{\infty}{\stackrel{1}{0}}$

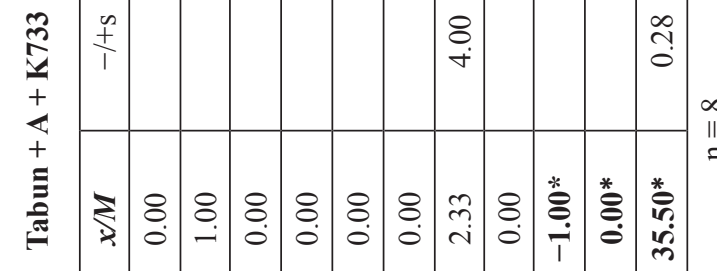

而

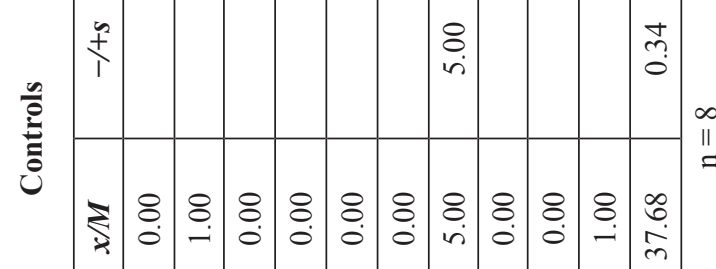

马्ّ

글

言.

号

开

品

نे

ลิ

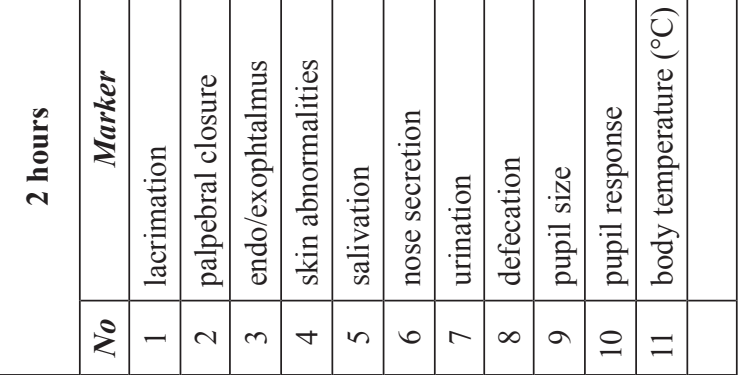


The functional observational battery (FOB) consists of 38 measurements of sensory, motor and autonomic nervous functions. Some of them are scored (Table 1), the others are measured in absolute units $(13,16)$. The first evaluation was obtained when tabun-poisoned rats were in the home cage. The observer evaluated each animal's posture, palpebral closure and involuntary motor movements. Then, each rat was removed from the home cage and briefly hand-held. The exploratory activity, piloerection and other skin abnormalities were noted. Salivation and nose secretion were also registered and scored. Then, the rats were placed on a flat surface which served as an open field. A timer was started for 3 min during which the frequency of rearing responses was recorded. At the same time, gait characteristics were noted and ranked, and stereotypy and bizarre behaviors and abnormal posture were evaluated. At the end of the third minute, the number of fecal boluses and urine pools on the adsorbent pad was registered. Reflex testing comprising recording each rat's response to a frontal approach of the blunt end of a pen, a touch of the pen to the posterior flank and to an auditory clic stimulus was also used. The response to a pinch on the tail and the ability of pupils to constrict in response to light were then assessed. These measures were followed by a test for the aerial righting reflex and by the measurements of forelimb and hindlimb grip strength, body temperature and finally hindlimb landing foot splay. The whole battery of tests required approximately $6-8 \mathrm{~min}$ per rat. Motor activity data were collected shortly after finishing the functional observational battery, using an apparatus for testing of a spontaneous motor activity of laboratory animals (constructed at the Faculty of Military Health Sciences, Hradec Králové, Czech Republic). The animals were placed for a short period (10 $\mathrm{min})$ in the measuring cage and their movements (total, horizontal and vertical activity) were recorded. The observer was blind to treatment condition.

Data collected with the FOB include categorial, ordinal and continuous values. Their statistical analyses were performed on a PC with a special interactive programme NTX (13). The categorial and ordinal values were formulated as contingency tables and judged consecutively by Chi-squared test of homogeneity, Concordance-Discordance test and Kruskal-Wallis test, respectively. The continual data were assessed by successive statistical tests: CI for Delta, Barlett test for Equality of Variance, Williams test and Test for Distribution Functions. The differences were evaluated at the significant level $\mathrm{p}<0.05$.

\section{Results}

The results of the experiments related to the measurement of tabun-induced neurotoxicity at 2 hours following tabun poisoning are divided into three parts (activity and neuromuscular measures, sensorimotor and excitability measures and autonomic measures) (16) and summarized in Table $2 \mathrm{a}-\mathrm{c}$. While five non-treated tabun-poisoned rats died before the evaluation of tabun-induced neurotoxicity by FOB, all tabun-poisoned rats treated with atropine in combination with an oxime survived till the end of experiment.

The evaluation of tabun-induced neurotoxic signs at 2 hours following intoxication proved significant alteration of 32 observed parameters. Tabun produced passive behavior of rats during handling and retention, severe miosis, lacrimation, salivation, nose secretion and a decrease in muscular tone. The posture of tabun-poisoned rats was seriously altered and skin abnormalities were observed. Exploratory and rearing activities were significantly reduced, righting reflex was altered, clonic and tonic convulsions were observed, gait and mobility were impaired and ataxia was found. In addition, no reaction during a reflex testing consisting of recording each rat's response to the frontal approach of the blunt end of a pen, to the touch of the pen to the posterior flank, to an auditory click stimulus and to a pinch on the tail was found. The pupils of the tabun-poisoned rats did not constrict in response to light because of tabun-induced miosis. A significant decrease in forelimb and hindlimb grip strength and body temperature was also observed at 2 hours following tabun challenge. In addition, vertical and horizontal motor activity was markedly reduced (Table $2 \mathrm{a}-\mathrm{c}$ ).

Both newly developed oximes (K727, K733) in combination with atropine were able to prevent some tabun-induced signs of neurotoxicity observed at 2 hours following tabun challenge with the exception of alteration of posture, passive behavior of rats during retention, a decrease in muscular tone and rearing activity, the absence of touch and click response and pupil response to light, a decrease in forelimb and hindlimb grip strength, body temperature and vertical as well as horizontal motor activity (Table $2 \mathrm{a}-\mathrm{c}$ ). On the other hand, the ability of trimedoxime to eliminate tabun-induced signs of acute neurotoxicity was slightly higher compared to the novel oximes studied. It was not be able to eliminate or reduce alteration of posture, passive behavior of rats during retention, a decrease in muscular tone and rearing activity, the absence of pupil response to light, and a decrease in forelimb and hindlimb grip strength, body temperature and vertical as well as horizontal motor activity (Table $2 \mathrm{a}-\mathrm{c}$ ).

\section{Discussion}

The severe poisoning with nerve agents including tabun brings centrally mediated seizures that can rapidly progress to status epilepticus and cause irreversible seizure-related brain damage if left untreated (17). It is known that atropine alone fails to prevent nerve agent-induced acute neurotoxic effects (18). As the potential benefit of atropine alone to counteract the acute neurotoxicity of nerve agents is negligible, atropine should be combined with a reactivator (oxime) of nerve agent-inhibited AChE for the antidotal treatment of nerve agent poisonings to improve its neuroprotective efficacy.

Generally, the ability of currently available oximes to eliminate tabun-induced acute neurotoxic effects is relative- 
ly low (19). Among them, trimedoxime seems to be the most effective to counteract tabun-induced acute neurotoxicity in rats although it is not able to completely eliminate or at least reduce all tabun-induced signs of neurotoxicity in the case of lethal tabun poisoning, either (18). Therefore, new oximes with higher potency to counteract tabun-induced acute neurotoxicity are still searched to increase the efficacy of antidotal treatment of acute tabun poisonings.

The ability of oximes to reactivate nerve agent-inhibited $\mathrm{AChE}$ in the brain is one of the most important factors influencing their potency to counteract acute neurotoxicity of nerve agents mostly caused by the irreversible inhibition of $\mathrm{AChE}$ in the brain (20). Bispyridinium oximes are generally more effective to reactivate nerve agent-inhibited AChE than monopyridinium oximes, however, their ability to penetrate across blood-brain barrier (BBB) is lower, in maximum of $6 \%(21,22)$. Therefore, a design of newly developed oximes should respect not only the goal to increase their reactivating efficacy via higher affinity to $\mathrm{AChE}$ but also the goal to increase their BBB penetration as much as possible. It was demonstrated that proper length between covalently connected proper peripheral site ligand and a non-ionic part containing nucleophilic aldoxime in the structure of AChE resulted in higher reactivation potency (23). From this point of view, AChE reactivators consisting of $\mathrm{AChE}$ proper peripheral site, ensuring the affinity to $\mathrm{AChE}$ and highly nucleophilic moiety (e.g. aldoxime, ketoaldoxime) capable of BBB permeation with balanced chemical-physical properties represent a very promising area in drug development against nerve agent poisoning (24). As the limitation of BBB penetration of bispyridinium oximes is caused above all by the presence of two quaternary nitrogens in their structure, uncharged reactivators represent a new hope in a way of increased bioavailability in the central compartment and better therapeutic management of nerve agent poisoning (25).

The experience from long-term oxime development work and the data from structure-activity relationship studies realized at our Department of Toxicology and Military Pharmacy were used for the chemical structure prediction and synthesis of both novel oximes studied (26-29). Both newly developed bispyridinium oximes (K727, K733) were designed as reactivators with aromatic connecting linker that was formerly found to be beneficial for the reactivation of cyclosarin, tabun and organophosphorus pesticides in vitro and in vivo (30-32). In addition, the oxime K733 was designed with ethoxycarbonyl moiety as a representative of carboxylic derivatives that were previously found to decrease toxicity of the reactivator (33). Therefore, the oxime K733 showed markedly lower acute toxicity than the oxime K727 (15).

To compare the neuroprotective efficacy of newly developed oximes (K727, K733) with trimedoxime, the ability of both novel oximes to eliminate or reduce tabun-induced neurotoxic signs and symptoms was slightly lower. As the neuroprotective efficacy of both novel oximes is not possible to explain exclusively by their central reactivating efficacy that was low or negligible (15), their neuroprotective effi- cacy could be also caused by their direct pharmacological effects such as inhibition of acetylcholine release, interaction with presynaptic cholinergic nerve terminals and/or with postsynaptic receptors (34-36).

\section{Conclusion}

The results presenting in this paper bring a novel information about the ability of both newly developed oximes to counteract some acute neurotoxic signs and symptoms induced by the lethal dose of tabun in spite of negligible central reactivating activity. However, the benefit of both novel oximes for neuroprotective efficacy of antidotal treatment of acute tabun poisonings is not so high to make the decision about the replacement of commonly used oximes (especially trimedoxime) in the antidotal treatment of acute tabun poisonings.

\section{Acknowledgements}

The authors wish to acknowledge Mrs. Jana Uhlírová and Eva Reslová for their skillful technical assistance. The study was funded by the grant of Ministry of Defense of the Czech Republic - "Long-term organization development plan 1011".

\section{References}

1. Lotti M. Organophosphorus compounds. In: Spencer PS, Schaumburg HH, eds. Experimental and Clinical Neurotoxicology, New York: Oxford University Press, 2000; 898-925.

2. Bajgar J. Organophosphate/nerve agent poisoning: mechanism of action, diagnosis, prophylaxis and treatment. Adv Clin Chem 2004; 38: 151-216.

3. Colovic MB, Krstic DZ, Lazarevic-Pasti TD, Bondzic AM, Vasic VM. Acetylcholinesterase Inhibitors: Pharmacology and Toxicology. Curr Neuropharmacol 2013; 11: 315-35.

4. Newmark J. Therapy for nerve agent poisoning. Arch Neurol 2004; 61: 649-52.

5. Eyer P, Szinicz L, Thiermann H, Worek F, Zilker T. Testing of antidotes for organophosphorus compoumds: Experimental procedures and clinical reality. Toxicology 2007; 233: 108-19.

6. Marrs TC, Rice P, Vale JA. The role of oximes in the treatment of nerve agent poisoning in civilian casualties. Toxicol Rev 2006; 25: 297-323.

7. Jokanovic M, Prostran M. Pyridinium oximes as cholinesterase reactivators. Structure-activity relationship and efficacy in the treatment of poisoning with organophosphorus compounds. Curr Med Chem 2009; 16: 2177-88.

8. Jokanovic M. Structure-activity relationship and efficacy of pyridinium oximes in the treatment of poisoning with organophosphorus compounds: a review of recent data. Curr Topic Med Chem 2012; 12: 1775-89.

9. Cabal J, Bajgar J. Tabun - reappearance 50 years later (in Czech). Chem Listy 1999; 93: 27-31

10. Ekström F, Akfur C, Tunemalm AK, Lundberg S. Structural changes of phenylalanine 338 and histidine 447 revealed by the crystal structures of tabun-inhibited murine acetylcholinesterase. Biochemistry 2006; 45: 74-81.

11. Hoffman A, Eisenkraft A, Finkelstein A, Schein O, Rotman E, Dushnitski TI. Adecade after the Tokyo sarin attack: a review of neurological follow-up of the victims. Mil Med 2007; 172: 607-10.

12. Yamasue $\mathrm{H}$, Abe $\mathrm{O}$, Kasai K, et al. Human brain structural changes related to acute single exposure to sarin. Ann Neurol 2007; 61: 37-46.

13. Frantik E, Hornychova M. Clustering of neurobehavioral measures of toxicity. Homeostasis 1995; 36: 19-25.

14. Jun D, Kuca K, Stodulka P, et al. HPLC analysis of HI-6 dichloride and dimethanesulfonate - antidotes against nerve agents and organophosphorus pesticides. Anal Lett 2007; 40: 2783-87.

15. Kassa J, Sepsova V, Tumova M, Horova A, Musilek K. A comparison of the reactivating and therapeutic efficacy of two newly developed oximes (K727, K733) with oxime K203 and trimedoxime in tabun-poisoned rats and mice. Bas Clin Pharmacol Toxicol 2015; 116: 367-71. 
16. Moser VC, Tilson H, McPhail RC, et al. The IPCS collaborative study on neurobehavioral screening methods: II. Protocol design and testing procedures. NeuroToxicology 1997; 18: 929-38.

17. Chen Y. Organopshophate-induced brain damage: Mechanisms, neuropsychiatric and neurological consequences, and potential therapeutic strategies. NeuroToxicology 2012; 33: 391-400.

18. Kassa J, Kunesova G. Comparison of the neuroprotective effects of the newly developed oximes (K027, K048) with trimedoxime in tabun-poisoned rats. J App Biomed 2006; 4: 123-34

19. Kassa J, Krejcova G. Neuroprotective effects of currently used antidotes in tabunpoisoned rats. Pharmacol Toxicol 2003; 92: 258-64.

20. Kassa J, Bajgar J, Kuca K, Jun D. Behavioral toxicity of nerve agents. In: Gupta RC, ed. Handbook of Toxicology of Chemical Warfare Agents, 2nd ed., New York, Academic Press Elsevier, 2015; 477-87.

21. Lorke DE, Kalasz H, Petroianu GA, Tekes K. Entry of oximes into the brain: A review. Curr Med Chem 2008; 15: 743-53.

22. Kalasz H, Nurulain SM, Veress G, et al. Mini-review on blood-brain barrier penetration of pyridinium aldoximes. J Appl Toxicol 2015; 35: 116-23.

23. de Koning MC, van Grol M, Noort D. Peripheral site ligand conjugation to a non quaternary oxime enhances reactivation of nerve agent-inhibited human acetylcholinesterase. Toxicol Lett 2011; 206: 54-9.

24. Masson P, Nachon F, Lockridge O. Structural approach to the aging of phosphylated cholinesterases. Chem Biol Interact 2010; 187: 157-62.

25. Korabecny J, Soukup O, Dolezal R, et al. From pyridinium-based to centrally active acetylcholinesterase reactivators. Mini Rev Med Chem 2014; 14: 215-21.

26. Cabal J, Kuca K, Kassa J. Specification of the structure of oximes able to reactivate tabun-inhibited acetylcholinesterase. Pharmacol Toxicol 2004; 95: 81-6.

27. Kuca K, Jun D, Musilek K. Structural requirements of acetylcholinesterase reactivators. Mini Rev Med Chem 2006; 6: 269-77.
28. Musilek K, Kuca K, Jun D, Dolezal M. Progress in synthesis of new acetylcholinesterase reactivators during the period 1990-2004. Curr Org Chem 2007; 11: 229-38.

29. Musilek K, Dolezal M, Gunn-Moore F, Kuca K. Design, evaluation and structureactivity relationship studies of the AChE reactivators against organophosphorus pesticides. Med Res Rev 2011; 31: 548-75.

30. Musilek K, Holas O, Kuca K, Jun D, Dohnal V, Dolezal M. Synthesis of a nove series of non-symmetrical bispyridinium compounds bearing a xylene linker and evaluation of their reactivation activity against tabun and paraoxon-inhibited acetylcholinesterase. J Enzym Inhib Med Chem 2007; 22: 425-32.

31. Nurulain SM, Lorke DE, Hasan MY, et al. Efficacy of eight experimental bispyridinium oximes against paraoxon-induced mortality: comparison with the conventional oximes pralidoxime and obidoxime. Neurotox Res 2009; 16: 60-7.

32. Musilek K, Holas O, Misik J, et al. Monooxime-monocarbamoyl bispyridinium xylene-linked reactivators of acetylcholinesterase - synthesis, in vitro and toxicity evaluation, and docking studies. ChemMedChem 2010; 5: 247-54.

33. Kassa J, Karasova J, Bajgar J, Kuca K, Musilek K, Kopelikova I. A comparison of the reactivating and therapeutic efficacy of newly developed bispyridinium oximes (K250, K251) with commonly used oximes against tabun in rats and mice. J Enzym Inhib Med Chem 2009; 24: 1040-4.

34. Van Helden HPM, Busker RW, Melchers BPC, Bruijnzeel PLB. Pharmacological effects of oximes: how relevant are they? Arch Toxicol 1996; 70: 779-86.

35. Sürig U, Gaal K, Kostenis E, Trankle C, Mohr K, Holzgrabe U. Muscarinic allosteric modulators. Atypical structure-activity-relationships in bispyridinium-type compounds. Arch Pharm 2006; 339: 207-12.

36. Niessen KV, Tattersall JEH, Timperley CM, et al. Interaction of bispyridinium compounds with the orthosteric binding site of human $\alpha 7$ and Torpedo californica nicotinic acetylcholine receptors (nAChRs). Toxicol Lett 2011; 206: 100-4.

Received: 05/11/2015

Accepted in revised form: 03/12/2015

\section{Corresponding author:}

Prof. Jiří Kassa, M.D., CSc., Faculty of Military Health Sciences, Trebešská 1575, 50001 Hradec Králové, Czech Republic; e-mail:kassa@pmfhk.cz 